\title{
SOCIAL MEDIA: AN EXPLORATION OF THE OUTCOMES OF SOCIAL MEDIA USE FOR HOMELESS YOUTH
}

\author{
By \\ Jennifer Donath, BSW, Ryerson University, 2017 \\ An MRP \\ presented to Ryerson University \\ in partial fulfillment of the \\ requirements for the degree of \\ Master of Social Work \\ in the Program of \\ Social Work
}

Toronto, Ontario, Canada, 201

(C) Jennifer Donath 2017 


\section{AUTHOR'S DECLARATION}

\section{AUTHOR'S DECLARATION FOR ELECTRONIC SUBMISSION OF A MRP}

I hereby declare that I am the sole author of this MRP. This is a true copy of the MRP, including any required final revisions.

I authorize Ryerson University to lend this MRP to other institutions or individuals for the purpose of scholarly research

I further authorize Ryerson University to reproduce this MRP by photocopying or by other means, in total or in part, at the request of other institutions or individuals for the purpose of scholarly research.

I understand that my MRP may be made electronically available to the public. 


\section{ABSTRACT}

Social Media: An Exploration of the Outcomes of Social Media Use For Homeless Youth Master of Social Work, 2017

Jennifer Donath Program of Social Work, Ryerson University

The purpose of this project was to explore how young adults are experiencing relationships when using social media. Using a qualitative design young adults between the ages of 16-25 were asked questions about their experience with social media in the city of Toronto. Qualitative interviews were conducted with three homeless participants who used social media and had access to the internet and a mobile device. The researcher analyzed the data by looking for themes within the participant's answers. Discussion focuses on the impact of social media, their experiences as a homeless youth and the interaction with social media on a daily basis. The findings also suggest future research for technology amongst homeless youth. 


\section{ACKNOWLEDGEMENTS}

I am grateful to all the Ryerson professors who have assisted me along this journey. Especially my MRP supervisor Gordon Pon, who has been a great instructor and support.

To the amazing participants in this study: thank you for your time, your eloquence and your dedication to this field.

A very special thank you goes out to my favorite three; Alan, Quinn and Ivy. Your flexibility, and confidence in me pushed me to the end. 


\section{DEDICATION}

To all the participants in this study who generously donated their time and told their story. May you continue to share your voice and journey. 


\section{$\underline{\text { Table of Contents }}$}

Introduction 1

Literature Review

Theoretical Framework $\quad 19$

Methodological Approach $\quad 24$

Analysis $\quad 28$

Findings 34

Discussion $\quad 35$

Limitations of Study $\quad 38$

Implications $\quad 40$

Conclusion $\quad 41$

References 43

Appendix A. Consent Form 47

Appendix B. Flyer 51

Appendix C. Interview Questions 53 


\section{Introduction}

There has been a substantial amount of research literature written independently on two phenomena - social media and homelessness among youth (Shields-Nordness, 2015). However, very few scholarly articles have tackled the intersection of the two and explored the potential impact that one phenomenon may have on the other (Shield-Nordness, 2015). My Major Research Paper (MRP) will examine the impact of social media on the homeless youth population. It will attempt to capture the youth's personal experiences and stories of their using social media. Social media may be a crucial tool available to homeless youth which offers opportunities for them to reach out to social influences beyond their physical surroundings. It may offer them connections to various online groups and communities to find people with relevant experiences, thoughtful insights, and common interests. On the other hand, it may also allow a much needed outlet for personal expression and cathartic release. If homeless youth experience helpful outcomes and impact through their use of social media, then it may be important for social service providers to offer a tool to increase the use of social media among homeless youth and potentially redirect them on an alternate path towards future opportunities.

Homeless youth are one of the most marginalized groups in our society. Not only do they lack some of the most basic necessities such as affordable housing, sustenance, and financial stability, they also struggle with a societal indifference to their plight and the challenges they face. Increasing numbers of runaway and homeless youth have become a serious social challenge to policy makers, human service providers, and communities (Lindsey, Kurtz, Jarvis, Williams, \& Nackerud, 2000). In mainstream media, homeless youth often encounter disparaging comments and are blamed for their own problems. Media has framed homeless youth in both an unflattering and negative manner, creating a stigma that is hard to shake. Homeless youth rarely 
have opportunities to tell their own stories and larger society has not been presented and informed with images of possibility or change from homeless youth. This socially constructed perception and devaluation facilitated by the media tends to lead to apathetic public and unmotivated politicians who fail to deem this issue a priority and fail to allocate money and time towards creating adequate supports and resources that may serve to decrease the rates of youth homelessness.

For the purposes of this study, the Canadian Homeless Research Network's (2012) definition of homelessness will be used:

Homelessness describes the situation of an individual or family without stable, permanent, appropriate housing, or the immediate prospect, means and ability of acquiring it. It is the result of systemic or societal barriers, a lack of affordable and appropriate housing, the individual or household's financial, mental, cognitive, behavioral or physical challenges, and/or racism and discrimination. Most people do not choose to be homeless, and the experience is generally negative, unpleasant, stressful and distressing (p. 1).

This definition includes individuals who are living on the streets, staying in emergency shelters, those who are provisionally accommodated in places like hospitals, jails or couch surfing, as well as those who are at risk for becoming homeless due to precarious housing stability. For youth in particular, the experience of homelessness is never homogenous. A multitude of factors interact that contribute to the development of a particular youth without adequate or safe shelter. These factors include broad macro level societal issues such as lack of affordable housing, racism and discrimination, as well as micro level factors such as an individual's physical health, mental health or substance use. 
Homelessness among young people continues to remain a serious social issue. It is estimated that 10,0000 youth will find themselves living on the streets of Toronto and struggling with various challenges that tend to accompany homelessness (Curtis, 2013; CHRN, 2012). These challenges include physical, sexual, mental health, health concerns, poverty, and addictions. Homeless youth suffer from a lack of basic necessities such as proper nutrition, adequate clothing and the stability that a fixed address can provide. Moreover, and even more significantly, homeless youth can lack confidence, a feeling of belonging, and a connection to peers and others that can provide a sense of hope to propel them out of their current situation (Curtis, 2013; CHRN, 2012).

The first recognizable social media site, Six Degrees, was created in 1997 (ShieldsNordness, 2015). It enabled users to upload a profile and make friends with other users. In the two decades since, social media platforms like Facebook, Twitter, and Instagram have become omnipresent and are an integral part of the identity and daily lives of hundreds of millions of users. Social media has become especially vital in the lives of young people, helping them to forge friendships, community, and sense of belonging. Social media allows them to build relationships, offers opportunities for entry into new social and virtual worlds, and makes it easier to share experiences.

My personal connection to this study is that I have been practicing as a housing worker when I first graduated from Ryerson University’s Bachelor of Social Work program. I have been fortunate working with the homeless population in my professional career for the last several years. As a graduate from this program, I have learned to critically locate, analyze, and challenge institutional and structural oppressions. In my personal life, I am a white female, and mother of two young girls living in a secure home in Toronto, Ontario. I wanted to take my 
professional experience and apply it to a topic I feel very passionate about. I am passionate about improving the life of others, and breaking down the stereotypes we hear so frequently. I have many privileges in my life. Although I am not homeless myself, I believe that I have an obligation to attempt to break down some of the barriers that homeless youth encounter on a daily basis. Meaningful interactions and raising consciousness can develop a process of recognizing and discovering the privilege and oppressions in one's personal life. Systematically not all children have a fair advantage, as a social worker I want to improve upon, and acknowledge the inequity in our society that puts homeless youth at a disadvantage due to marginalization, racism, stigma, and other societal oppressions.

Furthermore, this study will initiate a dialogue about homeless youth who use social media on a regular basis. These youths will consist of those primarily living in shelters who have access to personal mobile devices and computers and are be able to share their connection to social media. The study will be located in the city of Toronto and hopes to capture the personal stories of the homeless youth.

\section{$\underline{\text { Literature Review }}$}

\section{$\underline{\text { Social Media }}$}

By definition, social media involves people connecting with others using electronic communication. These "others" may be friends, family, romantic partners or "strangers" that are not known in an offline context (Subramanian, 2010). On a larger scale, social media has had a huge impact on bringing large issues together as a way to organize and mobilize social forums, campaigns and community organizations. On Facebook, hundreds of groups and pages exist to 
assist people struggling with similar problems allowing them to mobilize and advocate for themselves. On Twitter, conversations on important issues have been started and gone viral, confronting and challenging the status quo and forcing people to take notice.

\section{$\underline{\text { Homeless Youth }}$}

Homelessness among young people continues to remain a serious social issue. It is estimated that 10,000 youth will find themselves living on the streets of Toronto each year (Edidin, Ganim, Hunter, \& Karnik, 2012) and struggling with the various issues that tend to accompany homelessness. These issues include physical, sexual, and mental abuse, health concerns, poverty, and addictions (Edidin et al., 2012). Homeless youth suffer from a lack of basic necessities such as proper nutrition, adequate clothing and the stability that a fixed address can provide. Moreover, and even more significantly, homeless youth can lack confidence, a feeling of belonging, and a connection to peers and others that can provide a sense of hope that propels them out of their current situation (Maczewski, 2002).

Youth homelessness refers to youth who are homeless, at risk of homelessness or caught in a cycle of homelessness for whatever reason. The definition of youth as it pertains to homelessness ranges from as young as 12 to as old as 29 years old (CHRN, 2012). Most often, however, youth are defined as 16 to 24 years old. They are not living with a family in a home and they are not under the care of child protection agencies. Often defined as living in a cycle of homelessness, this can mean being temporarily sheltered or living in crowded or unsafe conditions (Zide \& Cherry, 1992). 
The most cited cause of youth homelessness is family breakdown or family conflict (Edidin, et al., 2012). Family breakdown may include poor family functioning, unstable home environments, socioeconomic disadvantage, and separation from parents (Edidin et al., 2012). Parental drug and alcohol use is also frequently cited as a reason for leaving home. Parental substance use is often associated with parental abandonment, family violence, and neglect, as well as sexual, physical, and psychological abuse (Edidin et al., 2012; Merscham, Van Leeuwen, \& McGuire, 2009). Additional factors that often lead to youth homelessness are out- of-home placements, or aging out of foster care (Merscham et al., 2009), as well as family conflict from identifying as part of the lesbian, gay, bisexual, transgender or questioning (LGBTQ) community (Edidin et al., 2012). The LGBTQ community face multiple barriers and discrimination in the community. Cukier \& Daniel (2015) point out that "Racialized LGBTQ homeless youth are even more reluctant to access existing general resources, agencies, and service providers for fear of social stigmatization and even violence, particularly for those youth who self-identify as transgendered" (p.4). Racial profiling has also become a problem, as "Profiling, whether social and/or racial, refers to the differential and/or discriminatory treatment attributed to one's race or skin color, sexuality, or gender orientation, or one's negatively perceived social status resulting from age or income level" (Cukier \& Daniel, 2015, p.5).

The literature also tends to focus on Indigenous youth, which comprises a large part of Toronto's homeless population. In the 1996 census, Aboriginal peoples constituted 3.8\% of the population, while in the 2001 census this figure rose to $4.4 \%$ (Baskin, 2007). One main reason for the homelessness among Aboriginal youth is attributed to colonization, where Aboriginal people were taken from their family and community and placed into Residential Schools. Here they were made to follow the Eurocentric dominant viewpoint, without any knowledge of their 
religious ceremonies and spiritual practices (Baskin, 2007). Therefore, social and political conditions have placed them in a disadvantaged position contributing to systemic unemployment, low wages or lack of income, loss of housing, racism, discrimination, and cultural and geographic displacement (Baskin, 2007).

The literature on homelessness should focus more on studies told by an Indigenous youth's viewpoint, and not by the researcher, as in most cases the researcher does not selfidentify as Indigenous. Therefore, findings can be easily misinterpreted or misconstrued, and findings could be inaccurate or pose facts that are untrue and false, which leads to unfair representation of the literature and history.

\section{Social Media and Youth}

There are many popular social media sites accessed by youth. These include but are not limited to: Facebook, LinkedIn, Twitter, YouTube, Pinterest, Instagram, Snapchat, Myspace, Flickr, WordPress, Blogger, Typepad, LiveJournal, Wikipedia, Wetpaint, Wikidot, Second Life, Reddit, Lulu and many others (Shields-Nordness, 2015). Social media has changed the way young adults communicate. Communication has traditionally been from one person to another and now people can communicate with hundreds of people at one time. There has also been an opposite effect, as some research has pointed to the notion that social media usage among youth has caused isolation and less communication face-to-face. However, there has been a high jump in social media usage over the last few years. Maczewski (2002) argues that youth actively using online communication today are developing new ways of learning, new language and new values. A good deal of research has focused on the ways in which social media has changed the 
way of life for young adults. It has completely altered the way they interact with each other, the way they share information, the way they define experience, and the way they relate to themselves and others. While each social media site features different tools and methods of engagement, they have a commonality in that at their core they offer an opportunity for people to establish connections and friendships (Boyd \& Ellison, 2008).

\section{Social Media and Homeless Youth}

Homeless youth often experience feelings of loneliness, isolation and rejection and have difficulty making connections with other people. The relative lack of resources that accompany being homeless might suggest that homeless youth have lower levels of internet use. However, new research has revealed that internet use is pervasive among these youths. Recent studies have found that more than $80 \%$ of homeless youth get online more than once per week (Rice, Monro Barman-Adhikari, \& Young, 2010). Given that a majority of youth has access to technology that would allow them to utilize social media, we need to learn more about whether this access can have a positive impact. While there has been a great amount of work on homeless youths' experiences on the streets, especially the way in which they enter, sustain or exit street life, relatively little is known about their social media habits and its effects and potential benefits on their psyche and on their long term outcomes.

A common theme found throughout the literature is that homeless youth have fewer personal and social resources compared to others their age, which contributes to their isolation, loneliness, and feelings of helplessness. Given their life context, social media may act as a resource for these otherwise resource-poor youth in many ways (Rice et al., 2010). Social media 
may bring on an environment conducive to, "learning, confidence, and self- empowerment" (Sanyal, 2000, p.144). Social media provides them with an opportunity to share with and learn from people who, although not geographically connected, may share similar experiences and feelings. Social networking technologies allow homeless youth to easily communicate with family and friends, which given their tenuous circumstances, may be more easily done online than face-to-face. In one study, $60 \%$ of youth reported using social networking websites to communicate with family and friends (Rice et al., 2010). Forging strong connections is associated with positive health outcomes and long-term benefits in terms of socialization. Social media can act as a constant reliable source for them to stay connected because it is always there for them when accessible. For example, the use of mobile devices also makes social media extremely accessible. Mobile devices have also been known to further enhance one's use of social media, as the accessibility is at their fingertips (Shields-Nordness, 2015).

\section{$\underline{\text { Social Capital }}$}

Two research studies used the social capital research paradigm for thinking about how online social interactions may facilitate resource seeking for homeless youth. Social capital can be described as a property of relationships and represents an investment in relationships that have expected returns (Rice, Monro, Barman-Adhikari \& Young, 2013). Work on homeless youth has repeatedly demonstrated that housing and employment are critical resources, which can lead youth towards long-term stability and away from homelessness (Rice et al., 2013). Online activities not only allow homeless youth to search for jobs, but it also allows them to access critical members of their social networks who can assist them in locating resources. The face-to- 
face networks of homeless youth are highly marginalized from mainstream housed society and are generally comprised of other homeless youth. In these two studies, the purpose of the research was to expand on prior research and examine the wide-ranging ways in which homeless youth use the internet and social media. The studies looked at the social context of their use, and how it might facilitate connections to positive relationships and online resource seeking. It also seeks to determine what the networks and social support systems for homeless youth are, and to identify correlations of these different sources of social support (Barman-Adhikari, Bowen, Bender, Brown \& Rice, 2016). Both studies used self-administrative surveys to gather a larger sample size and the Rice et al. (2013), study used a social network interview as well.

There are a few limitations to both of these studies. Firstly, the sample of both studies included only service-seeking homeless youth, which may prevent generalizing to more disconnected youth. A second limitation is conducting the research only using one single methodology: survey. Without conducting interviews, there is very little information to gain on the subjects and conclusions. Therefore, not gaining detailed information on social media can be problematic (Barman-Adhikari et al., 2016). The study is limited in personal experiences, and detailed information. Hence, the research is limited in its findings and further research needs to address these issues in the future.

\section{Social Media: A Source of Information}

Social media has become increasingly popular among different user groups. Although primarily used for social purposes, some social media platforms (e.g. Wikipedia) have been emerging as important information sources. Some populations are more likely to use computers than others. Homeless individuals tend to be less educated and have lower income levels than 
other population groups. However, one recent study found that a substantial proportion (44\%) of homeless individuals have mobile telephones they use to maintain contact with family, friends, and service providers (Eyrich-Garg, 2011). Having access to mobile telephones allows the individual the opportunity to stay connected with their peers and maintain relationships, and allows for information to be obtained and shared.

Social media has had an impact on creating a health benefiting network for homeless youth. As Rice (2010) suggests in his study examining the role of social networks and social networking technology in the condom-using behaviors of homeless young people, access to social networking technology e.g., the internet, cellular phones, and text messaging, may improve the sexual health of homeless young people. For homeless young people, the benefits of social networking technology are likely to be related to the people with whom they are communicating. It is entirely likely that the young homeless population, though resource poor, will use social networking technologies to maintain their relationships with home-based peers. Indeed, one study of homeless young people in Los Angeles reported that they accessed the internet an average of 4.4 days each week, and used social networking websites such as Myspace and Facebook about 3.3 days each week to connect with friends, family, and employers (Rice, Kurzban, \& Ray, 2010). Homeless adolescents reported surprisingly high levels of internet use, accessed primarily through free, public locations. Moreover, homeless youth are using the internet and social networking sites to reach out to a broad set of social network ties, including not only street-based ties, but also family and home-based peers (Rice, Monro, Barman-Adhikari \& Young, 2010). 


\section{Mental Health, Homelessness \& Networking}

Homelessness has been associated with numerous adverse outcomes across multiple domains. The detrimental effects of homelessness on cognitive and academic functioning, financial stability, and mental and physical health have been consistently noted in the literature (Lindsey et al., 2000). Whereas some of these effects may be short-lived and limited to the period of homelessness, others are more enduring in nature. The literature has consistently reported high levels of psychiatric disorders among homeless youth including depression, anxiety, substance use, posttraumatic stress disorder, and psychosis (Rice, Kurzban, \& Ray, 2010). The lifetime prevalence of psychiatric disorders is almost twice as high for homeless youth compared with their housed peers (Edidin et al., 2012). The longer adolescents are homeless, the less likely they are to have pro-social peers, and the more likely the proportion of antisocial and risk-taking peers in their networks increases (Rice et al., 2013). Moreover, the social location of the relationship (street versus home community) contributes to adolescents' risk behavior. Homeless adolescents who retain prosocial, home-based peers are less likely to engage in high-risk behavior (Rice et al., 2010). Modern social networking technologies such as email, cell phones, and social networking websites (e.g., Facebook, Myspace) are facilitating connections to pro-social, home-based ties for homeless adolescents (Rice et al., 2010).

Homeless adolescents report connecting to a wide array of street-based, family and home-based ties using technologies such as Facebook, Twitter and Instagram (Rice, Milburn \& Monro, 2011). Pierce (2009) reveals in his research that teens and youth are using socially interactive technology to communicate with others and it appears that social anxiety is influencing this use, or at least may be serving as a substitute for face-to-face communication. Findings also indicated that females reported feeling less comfortable in social situations, 
experiencing more social anxiety than males. In addition, the results showed that females who were socially anxious, tended to use social information technology (SITs) more than males in order to communicate and interact with others. Females also reported feeling more comfortable talking through text message or social online sites than face-to-face (Pierce, 2009).

There are several important findings from this literature on social networking technology. First, social networking technology (i.e. internet and social media) was a critical resource connecting homeless adolescents to their non-substance-using home-based ties. This also included the use of mobile phones. Approximately $50 \%$ of adolescents had a parent in the social network and nearly $75 \%$ had a homebased tie with whom they kept in touch via social networking technology (Rice et al., 2011). Positive influences were a subset of these overall connections, with nearly one third of adolescents having a non-substance-using parent and nearly 40\% having a non-substance-using home-based peer (Rice et al., 2011). These results buttress recent findings and suggest that despite their physical dislocation from home (and in most cases, school), homeless adolescents continue to remain connected to positive home-based social ties.

These findings have important implications to create effective peer-based models for homeless youth, and perhaps other marginalized and dislocated youth. Prevention models that only utilize face-to-face ties to street-based youth would appear unwise and provide limitations. Limitations in these studies were identified as improving research through conducting additional qualitative based research for more comprehensive detailed responses as to the reasons using online sites and further supports needed. Limitations also include a lack of clear and consistent definitions of the constructs of homelessness, youth and chronicity. This limits the researcher's ability to draw conclusions about the vulnerable population as a whole and to make meaningful comparisons about subgroups of homeless youth (Rice et al., 2011). Researchers have used 
various methodologies to study this population, which often makes it difficult to compare results of studies, and therefore, difficult to draw on empirically-supported conclusions about many of the issues homeless youth face. Moreover, higher quality studies are needed which move beyond convenience samples and recruit from multiple sources and from multiple cities so that the findings can be generalized more broadly. Perhaps, using a multi-method data collection would further strengthen study results.

\section{Relationships and Social Media Use}

Social media has changed the way youth experience their world online. It has changed the way they communicate with each other. Social media is changing relationships among youths. As it becomes increasingly popular, more interpersonal relationships are being formed through this way of communication and connecting (Maczewski, 2002). Text messaging is thought to be having the biggest impact on youth's relationships with peers, parents, and romantic relationships. One of the most interesting concepts on the rise with social media and text messaging is how youths are able to form strong relationships online without ever meeting in person. Relationships are often formed with finding others online that have common interests, similarities and are part of the same social network (Maczewski, 2002). Maczewski (2002) looked at youth's perspectives online and revealed that youths can often go online when they are dealing with other stressors that make them feel isolated or alone, and therefore, turn to social media for feelings of comfort and connections. Research has demonstrated a significant relationship between loneliness, defined as social disconnection, and low self-esteem as well as between loneliness and various forms of coping. These findings indicate that social 
connectedness, self-esteem, and resilience are intricately linked and that improvement in one area may well contribute to improvement in the other (McCay et al., 2011).

In order to learn more about youth's relationships involving social media, there needs to be far more research conducted and studies need to be comprehensive in detail. One of the limitations of the findings is these studies went into very little detail, using a small sample size, which only gathered a small number of participants for their research study. It was also noted that research on social media and its connections are lagging behind (Gudagno, Muscanell, \& Pollio, 2013). Another area of critique when addressing relationships among youth is the discussion regarding whether social media is harming youth's experience in any way. The article makes reference that it is a possibility; however, future research needs to be done. Literature needs to focus on youth's own experiences and hear their voices and not be told from the observations or point of view of the researcher.

\section{Negative Effects of Social Media: Stigmatization and Cyberbullying}

Although negative effects of social media were of limited presence of stigmatization and cyberbullying were nevertheless identified by the homeless youth. According to literature studies, homeless youth are well aware of stigmatization and typically try to hide their homelessness or housing needs from social websites (Whitbeck and Hoyt, 1999). However, despite the fact that cyberbullying and stigmatization are still being faced by the homeless youth, in literature, this topic continues to be overlooked. Importantly, one qualitative study on social stigma determined that it has negative impacts on the mental health of homeless youth (Kidd, 2004) and should be addressed. Defined as an aggressive, deliberate, and repeated behavior inflicted by an individual to another through the use of computers, cell phones, and other 
electronic devices, cyberbullying appears to be frequent among adolescents. Meta-analyses identify prevalence rates varying from 20 to $40 \%$ and even up to $70 \%$ for some vulnerable groups (Hébert, Cénat, Blais, Lavoie, \& Guerrier, 2016). With youths' increasingly growing access to social media, which are used in all spheres of their lives, such platforms can be used to carry out acts of intimidation and violence, even in the context of dating violence. Recent studies have shown that young victims of cyberbullying present a higher level of mental health problems (psychological distress, low self-esteem, suicidal ideations) than non-victims do. The negative impact traditional bullying has on students who are victims of bullying is well documented. One meta-analysis conducted on peer victimization found that being a victim of cyberbullying was positively associated with depression, loneliness, increased social anxiety, decreased self-esteem, and lower social competence (Hawker \& Boulton, 2000). Patchin and Hinduja (2006) found that victims of cyberbullying experience feelings of sadness, anger, embarrassment, and frustration. Young adults who were victims of cyberbullying reported having decreased self-esteem, selfconfidence, and poorer relationships with friends (Price \& Dalgleish, 2010). Cyberbullying victimization has also been significantly related to an increased risk for suicidality among adolescents (Patchin \& Hinduja, 2006). In addition to the challenges and potential negative outcomes facing gay, lesbian and transgender youth, they were also often found to be the victims of harassment, racism, homophobia bullying, and more recently cyberbullying with the advent of such technology.

\section{Homelessness and Toronto: What is being researched in Toronto?}

Limited Canadian research has been conducted in the area of homeless youth. Studies of a national scope have been limited by using small convenience samples and by covering a broad 
topic area (Cameron, Racine, Offord \& Cairney, 2004). This makes it difficult to get a comprehensive view of the antecedents and lifestyles of Canada's homeless youth. Two studies focused primarily on the homeless issues facing Toronto youth population. Most studies on this group have been focused in large urban centers, such as Rice's work in Los Angeles, with only two studies in Toronto. The few studies that have been completed tend to focus on one aspect associated with youth homelessness, such as substance use, delinquency, or food scarcity (Cameron et al., 2004). Homeless youth reported external factors such as physical abuse, not attending school, involvement in substance use and abuse, depression and suicidal thoughts, and contact with police as the major themes associated with their reasons for homelessness in Toronto. The study conducted by Cameron et al., focused on a small suburb in Toronto consisting mostly of white, upper-middle class families. Not only was this a very small sample size but it was also a unique study on an invisible population group. It only focused on a very specific suburban neighborhood and only on one agency within that neighborhood. The Toronto study by McCay et al., (2011) suggests that providing a relationship-based intervention for street-involved youth may be promising. The youth that participated in the 6-week intervention experienced higher levels of social connectedness and demonstrated a trend toward decreased hopelessness compared with participants who did not receive the intervention. Taken as a whole, these results suggest that the observed benefits in social connectedness and trends toward improvement in hopelessness and mental health symptoms may be related to participation in the intervention and not just to the passing of time (McCay et al., 2011). Preventive measures to keep youth from experiencing homelessness should focus on school, family, and community level interventions. Reporting of negative school experiences is common in street-involved youth. Therefore, interventions which target youth who are isolated or disconnected from 
academic settings could impact their progression to homelessness (Cameron et al., 2004). Family interventions, such as counselling could also halt the progression to homelessness, as many youths are thrown out of their homes due to inappropriate behavior. Finally, community interventions, such as drop-in centers, are needed to offer youths alternatives and possibly reduce risk factors (Cameron et al., 2004). Overall, these findings suggest that multifaceted programs need to be more geographically widespread and in many more "atypical" communities.

\section{Conclusion}

In this review of the literature, only two published peer reviewed journal articles were located that focused on social media use by homeless persons. This creates limitations as there are very few research studies and a lack of information on the topic. A second limitation found throughout, is that the data is imprecise with respect to the usage of social networking technology. Unfortunately, the data does not differentiate among ties maintained through email, social networking websites such as Myspace or Facebook, a cellular telephone, texting, or even a landline phone accessed at a social service agency (Rice, 2010).

Furthermore, future studies will be needed to examine potential benefits or risks in the quality of life and related issues as they impact or are impacted by social media use. The studies examined also lack populations from a diverse backgrounds and across racial and ethnic groups. Further research studies would help to improve our understanding and more accurately reflect the diversity of homeless youth. In conclusion, a great deal more information about just how homeless young people utilize social networking technology is needed. 


\section{Theoretical Framework}

Anti-oppression is "one of the main forms of social justice oriented social work theory and practice today. It is a promising and exciting approach to the complexity of today's social problems, and approach that recognizes the context of multiple oppressions and responds to the growing need for fundamental reorganization of all levels of society including homelessness among youth.” (Baines, 2007, p. 4)

Homeless youth are one of the most marginalized groups in our society. Homeless youth struggle with major structural barriers such as; poverty, lack of affordable housing, problems in their family structure, racism, discrimination, struggles with sexual orientation, and lack of education (Panter-Brick, 2004). Not only do homeless youth lack some of the basic necessities, they also struggle with a societal indifference to their plight and the challenges they encounter daily. Anti-Oppressive Practice (AOP) is the theoretical perspective that informs my understanding of the social context in which homeless youth find themselves as well as the possible benefits of social media usage for this group. Anti-oppressive approaches such as making awareness about injustice and structural forces, realization of power and diversity, structural modification in the organization and sensitive services can make fundamental changes in youth's lives (Karabanow, 2004).

Anti-oppressive practice is a dynamic process based on the changing, complex patterns of social relations. The driving force of AOP is the act of challenging inequity. Opportunities for change are created by the process of the challenge. Challenges are not always successful and are often painful for the person or group being challenged or challenging. A challenge, at its best, 
involves changes at both macro- and micro-levels (Burke \& Harrison, 2002). Insufficient financial/welfare assistance, crowded and inconvenient shelters, inadequate food and ineffective services are the non-supportive systems which creates negative environments.

The AOP approach also allows for the possibility of transformation and change. Baines (2004) refers to transformation as, “a way of relieving people's emotional pain and immediate difficulties while simultaneously working to change the larger dynamics that generate inequity, unfairness, and social injustice" (p. 3). This quote suggests that transformation is possible both on a small and larger scale. Social media is still an emerging technology, but seemingly can be used as a tool to potentially assist with the ongoing issues of youth homelessness on both a micro and macro level. On a smaller scale, homeless youth can login to Facebook or Twitter and be granted a multitude of voices and perspectives that challenge the uniformity of stories told from the point of view of the mainstream media. They can have some of their pain and isolation alleviated by being able to access stories from peers that would be otherwise unavailable. They can share their own stories and find catharsis. They can feel like a part of a bigger whole where they may not be the oppressed. On a larger scale, social media has had a huge impact on bringing large issues together as a way to organize and mobilize social forums, campaigns and community organizations. On Facebook, hundreds of groups and pages exist to assist people struggling with similar problems allowing them to mobilize and advocate for themselves. On Twitter, conversations on important issues have been started and gone viral, confronting and challenging the status quo and forcing people to take notice.

The AOP approach includes the influences of Marxist, socialist and radical ideologies, structural/sociological understanding of intersecting oppressions and emancipatory and feminist perspectives (Sakamoto and Pitner, 2007). The ultimate goal of AOP is to build upon these 
theories and perspectives in order to eradicate oppression through institutional and societal changes (Sakamoto and Pitner, 2007). AOP can challenge oppressions and attempt to bring about social equality, social justice and change, and this can happen with social media as a tool to help youth reach out and navigate through the community; by forming relationships and groups.

In a discussion regarding the adoption of AOP into the social work profession, Dominelli (1996) provides a sufficient definition of the AOP framework as:

a form of social work practice which addresses social divisions and structural inequalities in the work that is done with people whether they be users ('clients') or workers. AOP aims to provide more appropriate and sensitive services by responding to people's needs regardless of their social status. AOP embodies a person centered philosophy; an egalitarian value system concerned with reducing the deleterious effects of structural inequalities upon people's lives; a methodology focusing on both process and outcome; and a way of structuring relationships between individuals that aims to empower users by reducing the negative effects of social hierarchies on their interaction and the work they do together. (p. 170-171)

Dominelli (1996) argues that the significance of AOP is that it seeks to make connections between different aspects of people's lives and considers a holistic approach to living (Dominelli, 1996). Social media can help shape relationships between homeless youth that empower feelings of hope, connections, community participation, advocacy, and feelings of togetherness.

Furthermore, Stergiopoulous et al. (2012) notes that AOP, in the context of service provision in the fields of health and social services, can be understood as a theory which guides practitioners to address the issues of dignity, human rights, and access to resources and power 
(Stergiopoulous et al., 2012). However, it is important to note that AOP is a relatively new practice within the social work profession as this scope of work was predominately guided by anti-racism principles in the past (Williams, 1999). McLaughlin (2005) revisits the notion that the profession of social work, which previously encompassed a commitment to social justice through Anti-Racism Practice (ARP), has now expanded to include the examination of interlocking oppressions within society (McLaughlin, 2005). In drawing similarities, Stergiopoulous et al. (2012) further adds that like anti-racism - which recognizes an unequal distribution of resources, privilege, power and resources at the expense of all other racial groupsanti-oppression theory recognizes the existence of power imbalances and provides a framework on how to address them (Stergiopoulous at al., 2012). On the other hand, Stergiopoulous et al. (2012) also highlight that the difference between anti-oppression and anti-racism lies in the fact that anti-oppression does not predefine oppression from a specific category or mechanism, whereas anti-racism takes race/racism as the point of entry in its analysis of oppression, power, and privilege (Pon, Giwa, \& Razack, 2016; Stergiopoulous et al., 2012). Thus, anti-oppressive social work practice aims to achieve a partnership between service users which challenges power relations and systemic forms of oppression. Sakamoto and Pitner (2007) suggest that AOP ultimately aims to change the structure and procedures of service delivery systems through macro changes including legal and organizational changes. This could ultimately open doors to affordable housing, employment opportunities, and more social services that are able to assist homeless youth utilize these services and supports. Furthermore, Sakamoto and Pitner (2007) also state that social workers utilizing the AOP model recognize that they are not the only ones who should assume responsibility to transform the injustices and oppressions of society, but rather it is the state which must assume a much larger role in this transformation (Sakamoto \& 
Pitner, 2005). According to Pon, Giwa, and Razack, (2016), “This suggests the need to look beyond the micro-level of oppression when working with service users to make sense of their experiences and transform oppressive social conditions" (p. 47).

A number of studies have advocated for the incorporation of AOP in the practice of effectively working with the homeless youth population to understand their needs and deliver suitable services. Social work researchers advocate for social workers who interact with homeless youth to incorporate an AOP framework and utilize a socio-political approach to promote structural changes to help their conditions. According to Baskin (2003), "Structural social work views social problems as arising from a specific societal context - liberal, neoconservative capitalism - rather than from the failings of individuals" (p. 65). Thus, structural social work's primary focus is the recognition that oppression lies at the core of social problems (Baskin, 2003). Rather than blaming the individual for their situation, this approach examines the structures that create barriers; for example, affordable housing, employment rates, patriarchy, capitalism, and racism (Baskin, 2003). Thus, such an approach acknowledges that history has an impact on groups of people and that a people's past (i.e. colonization) is linked to their present conditions of oppression. The AOP framework incorporates a socio-political approach to highlight the ways in which larger social, political, institutional and structural barriers hinder homeless youth's access to adequate and affordable housing (Baskin, 2003).

Furthermore, McLaughlin (2005) indicates that despite some controversy regarding the benefits of utilizing an AOP framework in the social work profession, a significant rise in the adoption of the practice is evident. Numerous social work programs, including homeless-serving agencies and housing services rely on the AOP framework to help empower clients and challenge systemic inequalities. The AOP model is one which guides the contemporary scope of 
social work practice for many service providers and therefore benefits from its inclusion in this study. The qualitative approach used in this study - which incorporates interviews with homeless youth will attempt to highlight the values of the AOP framework and the ways in which the youth attempt to address social differences and structural inequalities throughout the interview process.

\section{$\underline{\text { Methodological Approach }}$}

This qualitative study incorporates a phenomenological research design to analyze the ways in which social media impacts homeless youth. According to Finlay (2009) the phenomenological approach places emphasis on rich descriptions of phenomena as it is

concretely lived. Thus, for this study, the phenomenological research design is most appropriate as this study places emphasis on the detailed experiences of homeless youth using social media without adequate housing and other required needs (Finlay, 2009). In this research paper, I will explore the impact of social media usage on homeless youth living in the city of Toronto in a shelter or on the streets. I will attempt to capture the youth's experience using social media. Social media may be a crucial tool available to homeless youth which aids them to reach out to influences beyond their physical surroundings. It may offer them connections to various online groups and communities to find people with relevant experiences, thoughtful insights, and common interests. Throughout this research paper, social media will also give a voice, autonomy, and privilege to participants to share their experiences. By adopting a phenomenological design, this study incorporates the use of semi-structured, informal interviews and thus, allows participants to provide an individual perspective on some of the barriers at-hand 
while also suggesting new solutions or recommendations which may not be acknowledged in extant published academic work. It is important to note that the goal of this research design is not to produce findings which are generalizable to the larger population of homeless youth. Rather, the aim of the research is to obtain rich, detailed information of the experiences of the three youth's experiences of homelessness and social media usage.

This is a small, qualitative study that examines the lived experiences of homeless youth using social media to build on connections and community groups. A total of three qualitative interviews were conducted. This method was chosen as there was limited research regarding the relative impact social media has on our youth in contemporary society, particularly homeless youth populations. The criteria for selecting participants is that they must be homeless or had experienced being homeless, and have access to social media either by a mobile device or computer. The interviews were semi-structured and last one hour in duration. I used an interview guide with a list of semi-structured questions. The interviews were audio-recorded so that I could transcribe the interviews for the purpose of critical examination and in-depth analysis. I recruited participants through word of mouth and I used my professional contacts in the field to inform participants about my study. I have been working for a number of years as a professional social worker in the field of homelessness and was able to gather participants through my professional contacts. I created a script as part of my Research Ethics Board (REB) guideline that outlined my study to each participant and what is expected. This method provided an initial consent by participants to share contact information with me and for them to ask any further questions about the study. Further written consent was follow upon agreement to participate in an interview.

Participants were contacted by the researcher with a written dialogue explaining the nature of the study and its objectives/goals. As a social worker working in the community of 
homelessness, participants were also found through word of mouth and professional contacts by the researcher. The details of the research were explained to participants. Given the lack of research on this particular topic, I recruited three participants to capture more in-depth findings. Participation were voluntary and participants connected with me if interested. A date and location of interview was scheduled after consent forms were signed.

As required by the Ryerson University REB, which approved this research project, participants were informed of the nature of the study, specifically that they would have a chance to provide a narrative about their experiences as a homeless youth using social media. Participants were informed of steps being taken to ensure confidentiality prior to the beginning of the interview. They were provided with a copy of the consent and given a chance to read and make any inquiries they have regarding the consent form. After explaining the participatory nature of the interviews, each participant was asked to sign the consent form. All three participants agreed to participate and signed the consent form. All three participants also consented to the audio recording of their interviews for purposes of transcribing the data and coding. At any given time of the research, participants can withdraw from the research study, and information that was provided will be destroyed and not used in the final results of the research paper.

One hour in-depth interviews were separately conducted with each of the three participants. The location of each interview was agreed upon by the participant and researcher in a private community organization, in a confidential booked space. The location was a mutual location agreed upon by both participants and researcher. The interview is guided by semistructured interview questions approved by the Ryerson University REB. Questions posed to participants are meant to gather the lived experiences of homeless youth utilizing social media 
within the city of Toronto. The aim was to allow participants to reflect on their unique experience as a homeless individual and share their use and time spent on social media.

I collected the name, address (if they have one), and age of my research participants during the recruitment process so that I could facilitate arranging interviews and correspondence with the participants during the research process. Unfortunately, due to the transient lifestyle of homeless youth, I tried and scheduled the interview within a few days of meeting the participants in order to locate the participant, and conduct the interview. Information was kept confidential and securely stored electronically with password protection which will all be destroyed prior to publication. None of this sensitive information will ever be used in the research publication instead, pseudonyms will replace the names. Each interview is set for a one-hour period. Interviews were recorded and the audio from each recording was transcribed. After the interviews were conducted, follow-up work for each interview was completed (transcript, coding, interpretive comments), and the next step of the process occurred (Chase, 2003). This research study followed Chase's (2003) requirements for coding and transcribing. Transcripts were analyzed for emergent themes based on identical or similar content and placed into a few main categories. These themes were categorized into headings. Analysis focused on each distinct theme as its own topic followed by an examination of possible relationships between themes and how they may influence one another. Transcribed interviews were read and re-read in order to identify common and emerging themes after coding has been completed. Particular attention was paid to any ideas that were influenced by an AOP framework. Additional information is further discussed in the findings chapter.

This Major Research Paper (MRP) is intended to be of minimal risk to participants as every effort was made to keep identifying information private. While there may be some risk of 
potential issues resurfacing due to the nature of the topic, best efforts have been put in place to provide participants with outside supports if needed. During the interview, there was a potential risk that some participants may experience psychological discomfort when discussing experiences around their homelessness and other social issues. The risk of harm is low/minimal, however, during the interview process, there was a possibility for participants to experience some discomfort. During the interview I did periodic check-ins to ensure the participants are comfortable and not feeling anxious and/or upset. Participants were informed that this is a voluntary research project and that they were free to withdraw from the study at any time should they wish with no consequences. Participants were made aware that their data, in its entirety, will be destroyed at any time that they decide to withdraw from participation and, as such, will never be part of the final research paper. No participants withdrew from the study. I member checked with participants to ensure their statements are accurately represented and internal validity is maintained. Lastly, I attempted to disseminate the results to the community and to the three participants if they are interested in the overall findings of the paper. I feel this is very important as it gives participants recognition, and a voice to their experiences. The research paper can also assist with some changes to organizations. I hope to implement the findings of my research study into my future work as a social worker and within the community.

\section{$\underline{\text { Analysis }}$}

\section{Participants:}

A total of three participants $(n=3)$ were recruited for this study: two females and one male. All of the participants had experienced homelessness and reported using the internet and 
social media. Due to the general lack of consensus regarding homelessness, for the purposes of this study, "homeless youth" was identified as a group of individuals that either lacked or remain to be deficient of consistent residence. The recruited individuals were ethnically diverse and belonged to the same age category, ranging between 20-25 years of age (the exact ages of the participants were: 25,23 , and 20). These individuals were selected for the interview process on a voluntarily basis. All of the participants were informed of privacy and confidentiality of their answers, as well as presented with an option to withdraw from the study at any time during the interview process.

\section{The Interview Process:}

The following section presents a brief summary of the key findings from the interviews conducted with three participants. All of the interviews were conducted in a private space and administered in person. The duration of each interview was 60 minutes. The interviews were audio recorded, transcribed, and analyzed. While the interview guide partially directed the nature of the questions, a number of themes emerged which will be analyzed in this section. These analyzed themes were identified using a coding process.

\section{Measures:}

The demographic variables displayed in Table 1 were self-reported by the three interview participants. The measured variables include ethnicity, age, gender, the number of years homeless, and current living situation. The number of years homeless was estimated for each participant by subtracting their current age from the reported onset age of having homelessness 
experience. The mean and standard deviation were calculated for the age (mean $=22.66$, std. dev. $= \pm 1.45)$ and for the number of years homeless $($ mean $=1.36$, std. dev. $= \pm 0.34$ ) variables of the sampled group. The actual number of years homeless for the three participants were: $2,1.25$ (=1 year and 3 months), and 0.83 (=10 months). Gender was represented as male and female and was based on the self-identification. Current living situation was derived from the interview responses and categorized into three subsets:

1. Individuals that are without a home - living on the streets

2. Individuals with temporary housing - residing in shelters

3. Individuals with stable housing - have been housed or show an improved housing situation outside of shelters.

Table 1: Demographic Profile of Social Media - Using Homeless Youth $(n=3)$ in Toronto:

\section{Demographic Description}

\section{Gender:}

Female

Male

Ethnicity:

White

African American

Other/Non-Identified

Age:

Participant 1: 25

Participant 2: 23

Participant 3: 20

n $\%$

2

66.66

1

33.33

33.33

33.33

33.33

Mean

Std Dev

22.66

$\pm 1.45$ 
The Number of Years Homeless:

Participant 1:2

Participant 2: 1.25

Participant 3: 0.83

\section{Current Living Situation:}

Without a home

Temporary housing (i.e. shelter/group home)

Stable housing with past homelessness experience
Mean

Std Dev

1.36

$\pm 0.34$

The usage of the social media by the homeless youth variables are presented in Table 2.

The data presented below was derived from the participants' interview responses. The interview responses of the homeless youth were then screened, analyzed, and compared for the purposes of determining potential benefits and/or risks associated with homeless youths' online social media behavior. Gaining a greater understanding of the impact and the use of social media by the homeless youth individuals may prove to be useful when delivering interventions.

Table 2: The Usage of Social Media by the Homeless Youth in Toronto:

Question Variables and Responses:

Do you have access to social media?

Yes

No

How often do you use social media?

Multiple times per day

Once or twice per day $n$

$\%$

3

0

0

100

2

66.66

1

33.33 
Why do you use social media?

To Communicate and Share Thoughts

For Professional Networking

Has social media connected you to family/friends/community?

Yes

No

What social media sites do you use?

Facebook

Instagram

Twitter

LinkedIn

Are you part of a social network/online group/community?

Yes

No

Did you have a negative experience with social media?

Yes
3

100

2

1

1

66.66

1

33.33 
Types of negative experiences with social media:

Cyberbullying

\section{Homelessness -leading causes:}

Substance Abuse/Drug Addiction

1

Family Disputes/Arguments

2

66.66

What does being homeless personally mean to you?

Lost Sense of Belonging/Isolation

Loss of Self-Worth/Feeling Not Needed

Feelings of Uncertainty

Diminishing Mental Health

Loss of Comfort

Paranoia/Anxiety

Fear for Safety

Loss of Privileges
3

3

3

1

2

1

1

1
100

100

100

66.66

The results presented in Table 1 and Table $\mathbf{2}$ were derived directly from the participants' responses. Descriptive analyses were applied to obtain frequencies of the individual responses to 
the interview questions. The overlapping variables, where $n=2$ or $n=3$ indicate coinciding responses of the participants, and are therefore deemed as having a more significant value than those variables where $n=1$. The findings and implications of these interview-based results are discussed in the section below.

\section{Findings}

The results of the study on social media and homeless youth demonstrate that all of the participants had access to social media and that social media has helped homeless youth to connect with family, friends, or community. All of the participants reported using social media on daily basis, with $66.66 \%$ of individuals using it multiple times per day.

Among the available social media platforms, Facebook was used by all of the participants. Instagram use was reported by two participants $(66.66 \%)$, and Twitter with LinkedIn were less popular (33.33\%) among the homeless youth. All of the individuals reported that they use social media to:

\section{To Communicate and Share Thoughts}

2. To Gain Mental or Emotional Benefits

\section{To Socialize and Connect with Family and Friends}

Only one of the participants reported the use of social media platforms for professional networking. 
The results of this qualitative study also revealed that one of the participants has had a negative social media experience, which was attributed to cyberbullying and stigmatization of homeless individuals.

The responses of participants also showed that arguments and disputes with family members, as well as parental negligence were the leading cause of homelessness in youth $(66.66 \%)$. One of the participants had also reported drugs and substance abuse as a precursor to homelessness $(33.33 \%)$.

Perhaps one of the most interesting results was based on the responses of participants to the following interview question: "What does being homeless personally mean to you?". Interestingly $100 \%(n=3)$ of the participants indicated that homelessness made them feel:

\section{A Lost Sense of Belonging and Isolation}

2. A Loss of Self-Worth/Feeling Not Needed

\section{Uncertainty}

The other answers to this question associated homelessness to loss of comfort $(66.66 \%)$. Only one of the participants indicated that homelessness had a negative effect on mental health $(33.33 \%)$, resulted in paranoia/anxiety $(33.33 \%)$ and fear for safety $(33.33 \%)$.

Overall, the descriptive analyses of homeless youth's interview responses demonstrate that the benefits of social media use outweigh its potentially negative influences.

\section{$\underline{\text { Discussion }}$}

\section{Social Media: Human Connection and Mental Health}


There have been very few studies on the influence of social media among the homeless youth in Toronto. This qualitative interview-based study provides a number of important insights regarding the role of social media in the lives of homeless youth. Comparably to the housed youth, the participants of this study reported using the internet for social media access on daily basis and multiple times per day. According to this study, one of the most common responses for the use of social media by the homeless youth ( $100 \%$ of sampled individuals, $n=3)$ was to connect with family, friends, and community. This finding is consistent with the literature results, where social media use by the homeless individuals has been well documented (Leung 2006). These data indicate that while the life circumstances of homeless youth could have been different, using social media platforms allows them to connect with other individuals or access networks that may potentially provide them with social support (Rice et al., 2011).

All of the participants ( $100 \%$ of sampled individuals, $n=3)$ also stated that they use social media to communicate and share their thoughts, as well for the purposes of gaining mental and emotional self-benefits (see Table 2). On the other hand, only one of the participants used social media towards goal-oriented activities such as professional networking (33.33\% of sampled individuals). These findings are consistent with a study by Subrahmanyam et al. (2008), which showed that socialization is critically important to homeless youth and their mental health.

The interviewed individuals revealed having increased levels of happiness and self-worth while using social media by stating:

"I value anyone that adds me on social media because they are somewhat interested to see what is happening in my life... It is that moral boost that is the most important in using social media - not just catching up on what everyone is talking about." 
"I use social media to talk to my friends and it makes me feel like I'm there and more connected and better."

"It's not about what you have to say - it's about getting the opportunity to say something."

"If it wasn't for social media, I would have to be physically more social with people. Social media cuts down the time required to feel better about myself, cuts down the time I need to feel validated."

"I wanted somewhere to put my thoughts, so I signed up... If it was not for social media, people would not be who they are today. At different times in my life, I really learned a lot about myself and others through social media."

"I use it for sharing thoughts, different social thoughts about what's happening in the country, and political."

"I am very introverted and struggle with social anxiety and being social. Most of my relationships are over Facebook and Facebook chats."

"I use LinkedIn for keeping my own professional connections. I am very active on social media."

"Social media helps me grow as a person, how I want to portray myself."

"It's nice to have an anonymous Instagram account and be able to post what I'm feeling like today sucks and find that outlet for myself. That's where I found that venue for myself."

All of the above statements were directly quoted from the participant's interview answers. These responses attribute to the positive effects of social media on homeless youth. Participants described that using social media made them feel better about themselves. 
According to these statements, it is then possible that social media may have a therapeutic effect on the homeless youth.

The possibility of social media having a therapeutic effect on homeless youth is consistent with the description and the meaning of homelessness to youth. Interestingly when participants were asked "What does being homeless personally mean to you?", all individuals reported that to them, homelessness was identifiable with loss of self-worth and sense of belonging, as well as presence of uncertainty. It is possible that social media may act therapeutically, by filling this gap in homeless youth. Consequently, if social media is able to counter the feelings and emotions identified with homelessness in youth, then it has applications in fostering better mental health.

\section{Bridging Social Capital}

The findings of this study showed that bridging social capital was an important social media parameter for homeless youth. All of the participants reported using social media to communicate and share thoughts, to gain mental or emotional benefits, and to socialize and connect with family/friends. Homeless youth are using the social media and gaining these psychological and sociological benefits. Within a wider social context, the benefits of bridging social capital could be increased by facilitating social media access for homeless youth.

\section{Limitations of the Study:}

A number of important limitations arose from this qualitative study. Since the results were qualitative in nature, they were derived from a set of structured interview questions directed at three participants. The qualitative data was based on self-responses and it is possible that 
interviewed participants may have been over or underrepresenting the actual time being spent on the internet. However, the fact that participants were informed of privacy and confidentiality of their answers, as well as presented with an option to withdraw from the study at any time, has likely made their responses more honest and unbiased. It follows that mitigating social desirability and estimating the time spent online may have been impacted by error. The use of observational methods such as recoding the time being allocated towards the use of social media could have produced more accurate results. However, in the case of the homeless youth, whose living situation tends to be fluid, it is rather difficult to track down or observe these individuals for an extended period of time - making the implementation of such methods and data collection difficult.

The results and findings were also limited by the total number of the participants. The sample size of selected participants was three. However, the purpose of this study was to gain a deeper insight into the lives of homeless youth and their usage of the internet for social media. While drastic increase in the number of participants may have had the effect of impeding the qualitative nature of this interview-based research, having more participants could have led to findings that were more representative of the Toronto's homeless youth population and their use of social media.

Moreover, the current living situation of the participants only fit two categories - those with a temporary housing residing in a group home or shelter $(n=2)$, and those with a stable housing $(n=1)$. None of the interviewed individuals fit the category of living without a home $(n=0)$, which could have provided greater insights into the use of the social media by the homeless youths. However, due to the confidential nature and the time required to conduct the interviews, it was rather difficult to recruit individuals residing on the streets of Toronto. 
Importantly however, all three participants that were interviewed in this study had experienced literal homelessness (lived without a home/shelter on the streets) for some period of time in their lives. Similarly, the small sample size resulted in limited demographic and gender representations of the participants, as well as sexual orientation, and race - factors that also could have contributed to the findings of this study.

\section{Implications:}

Although this study is exploratory, the qualitative findings collected from three interviews have very important implications for interventions and policy practice related to homeless youth populations. Current data suggests the need for immediate attention for homeless youth programming. Further research is suggested to help develop ways to educate younger generations on the use of social media and texting and the implications it can have on their ability to connect and form healthy relationships with others.

This study showed that the use of social media and internet serve as important resources for the homeless youth in meeting their instrumental and social needs. Therefore, increasing internet accessibility and promoting the use of social media is essential for homeless youth. Policymakers may contemplate on funding streams for youth-serving agencies and develop computer laboratories to mitigate the currently existing problem of homeless youth.

The ubiquity of internet use among homeless youth also makes it possible to deliver interventions online. Previous studies demonstrate that intervention and prevention programs proved to be both, effective and valuable (Ybarra \& Bull, 2007). Increasing predominance of 
such programs may be used as a medium for the effective delivery of interventions for the homeless youth.

Clinical social workers need to be aware of the biases towards the use of social media when working with service users. This is the main means of communication for this age group and that will not change. As the technology and the ability to be connected increases the emphasis on using that technology as the main means of communication will continue to grow. The technology is not going away and it will become the new norm. It will be important to know how to connect with this age group and how to educate them on the importance of other means of communication.

Further research needs to be explored, preferably, this will be AOP research which will aim to capture the voices of youth that are homeless or living in a shelter setting. Future research should also explore possible benefits and practicalities of changing the way our present system represents homeless youth and provide more education and programming to better help promote equality, financial assistance, affordable housing, employment, and many more opportunities for youth.

\section{Conclusion:}

The findings of this interview-based qualitative study show that homeless youth access social media for instrumental purposes relating to their housing conditions. Homeless youth involved in this study reported a number of benefits from social media use, including: increased professional networking, connectivity between friends and family members, socialization and sharing of ideas, and improvement in mental health. Stigmatization and cyberbullying were among the negative aspects of social media use by the homeless youth. Given that social media 
could be accessed through a cellphone, which is a relatively inexpensive resource, perhaps making them more accessible to homeless youth should be considered. Providing homeless youth with a temporary cellphone access, may enable them to use social media as a coping mechanism, as well as stay connected, pursue higher level resources (i.e. employment and housing). This may help to alleviate the current problem of homeless youth, which in turn can lead to stability and self-growth. Overall, the findings of this study indicate that social media use is beneficial and therapeutic in nature, and that social media platforms improve both physical and behavioral patterns of homeless youth. This study also incorporated the framework of AntiOppressive Practice (AOP) to understand the oppression, marginalization, and exclusion that many recent homeless youth experience within Toronto's housing and rental markets; and how this has the ability to initiate the cycle of homelessness. Access to social media has created a network to help with the continued challenges and oppressions faced by youth. Further advocacy towards adequate housing, and better programming are slow, but steady, and can hopefully create mobilization for change. 


\section{$\underline{\text { References }}$}

Baines, D. (Ed.). (2011). Doing anti-oppressive practice: Building transformative, politicized social work. $2^{\text {nd }}$ Ed. Halifax, NS: Fernwood.

Barman-Adhikari, A., Bowen, E., Bender, K., Brown, S., \& Rice, E. (2016). A social capital approach to identifying correlates of perceived social support among homeless youth. Child Youth Care Forum, 45, 691-708.

Baskin, C. (2003). Structural social work as seen from an aboriginal perspective. In W. Shera (Ed.), Emerging perspectives on anti-oppressive practice (pp. 65-79). Toronto: Canadian Scholars Press.

Baskin, C. (2007). Aboriginal youth talk about structural determinants as the causes of their homelessness. A Journal on Innovation and Best Practices in Aboriginal Child Welfare Administration, Research, Policy, \& Practice, 3, 31-42.

Boyd, D., \& Ellison, N.B. (2007). Social network sites: Definition, history, and scholarship. Journal of Computer-Mediated Communication, 13, 210-230.

Burke, B., \& Harrison, P. (2002). Anti-oppressive practice. In Adams, R., Dominelli, L. \& Payne, M. (Eds.), Anti-oppressive practice (pp. 227-235). Basingstoke: Palgrave MacMillan Ltd.

Cameron, K., Racine, Y., Offord, D., \& Cairney, J. (2004). Youth at risk of homelessness in an affluent Toronto suburb. Canadian Journal of Public Health, 95, 352-356.

Canadian Homelessness Research Network (2012). Canadian definition of homelessness homeless hub. Retrieved from www.homelesshub.ca/CHRNhomelessdefinition/

Chase, S. E. (2003). Learning to listen: Narrative principles in qualitative research course. In R. Josselson, A. Lieblich, \& D.P. McAdams (Eds.), Up close and personal: The teaching and learning of narrative research (pp. 79-99). Washington, DC.: American Psychological Association.

Cukier, W. \& Daniel, L. (2015). The 360 Project: Addressing Racism in Toronto. Addressing the Discrimination Experienced by Somali Canadians. Radicialized LGBTQ Homeless Youth in Toronto. Toronto, ON.

Curtis, A. (2013). The brief history of social media. Retrieved from http://www2.uncp.edu/home/acurtis/NewMedia/SocialMedia/SocialMediaHistory.html

Dominelli, L. (1996). De-professionalizing social work: Anti-oppressive practice, competencies, and post-modernism. British Journal of Social Work, 26(2); 153-175. 
Edidin, J. P., Ganim, Z., Hunter, S. J., \& Karnik, N. S. (2012). The mental and physical health of homeless youth: A literature review. Child Psychiatry Human Development, 43, 354-375.

Eyrich-Garg, K. (2011). Sheltered in cyberspace? Computer use among the unsheltered 'street' homeless. Journal of Computers in Human Behavior, 27, 296-303.

Finlay, L. (2009). Debating phenomenological research methods. Phenomenology and Practice, $3(1) ; 6-25$.

Guadagno, R., Muscanell, N., \& Pollio, D. (2013). The homeless use Facebook? Similarities of social network use between college students and homeless young adults. Journal of Computers in Human Behavior, 29, 86-89

Hawker, D. S. J., \& Boulton, M. J. (2000). Twenty years' research on peer victimization and psychosocial maladjustment: A meta-analytic review of cross-sectional studies. Journal of Child Psychology and Psychiatry, 41(4), 441-455.

Hébert, M., Cénat, J. M., Blais, M., Lavoie, F. and Guerrier, M. (2016). Child sexual abuse, bullying, cyberbullying, and mental health problems among high school's students. Journal of Depress Anxiety, 33: 623-629.

Karabanow, J. (2004). Making organizations work: Exploring characteristics of anti-oppressive organizational structures in street youth shelters. Journal of Social Work, 4(1), 47-60.

Kidd, S. A. (2004). "The Walls Were Closing in, and We Were Trapped" A Qualitative Analysis of Street Youth Suicide. Youth \& Society, 36(1), 30-55.

Leung, L. (2006). Stressful life events, motives for Internet use, and social support among digital kids. CyberPsychology \& Behavior, 10(2), 204-214.

Lindsey, E. W., Kurtz, P. D., Jarvis, S., Williams, N. R., \& Nackerud, L. (2000). How runaway and homeless youth navigate troubled waters: Personal strengths and resources. Child and Adolescent Social Work Journal, 17, 115-140.

Maczewski, M. (2002). Exploring identities through the internet: Youth experiences online. Journal of Child \& Youth Care, 31, 111-129.

McCay, E., Quesnel, S., Langley, J., Beanlands, H., Cooper, L., Blidner, R., Aiello, A., Mudachi, N., Howes, C., \& Bach, K. (2011). A relationship-based intervention to improve social connectedness in street-involved youth: A pilot study. Journal of Child and Adolescent Psychiatric Nursing, 24, 208-215.

McLauglin K. (2005). From ridicule to institutionalization: Anti-Oppression, the state, and social work. Critical Social Policy, 25(3); 283-305.

Merscham, C., Van Leeuwen, J.M., \& McGuire, M. (2009). Mental health and substance abuse indicators among homeless youth in Denver, Colorado. Child Welfare, 8(2), 93-110. 
Panter-Brick, C. (2004). Homelessness, poverty, and risks to health: Beyond at risk categorizations of street children. Children's Geographies, 2(1), 83-94.

Patchin, J. W., \& Hinduja, S. (2006). Bullies move beyond the schoolyard: A preliminary look at cyberbullying. Youth Violence and Juvenile Justice, 4, 148-169.

Pierce, T. (2009). Social anxiety and technology: Face-to-face communication versus technological communication among teens. Computers in Human Behavior, 25, 13671372.

Pon, G., Giwa, S. \& Razack, N. (2016). Foundations of anti-racist/anti-oppressive social work practice. In Al-Krenin and Graham, J. (Eds.), Diversity and social work in Canada (pp. 3858). Don Mills, ON: Oxford University Press.

Price, M., \& Dalgleish, J. (2010). Cyberbullying: Experiences, impacts and coping strategies as described by Australian young people. Youth Studies Australia, 29(2), 51-59.

Rice, E. (2010). The positive role of social networks and social networking technology in the condom-using behaviors of homeless young people. Public Health Reports, 125, 588-595.

Rice, E., Lee, A., \& Taitt, S. (2011). Cell phone use among homeless youth: potential for new health interventions and research. Journal of Urban Health, 88(6), 1175-1182.

Rice, E., Monro, W., Barman-Adhikari, A., \& Young, S. D. (2010). Internet use, social networking, and HIV/AIDS risk for homeless adolescents. Journal of Adolescent Health, 47, 610-613.

Rice, E., Monro, W., Barman-Adhikari, A., \& Young, S. D. (2013). Internet and social media use as a resource among homeless youth. Journal of Computer Mediated Communication, 19, 232-247.

Rice, E., Milburn, N., \& Monro, W. (2011). Social networking technology, social network composition, and reductions in substance use among homeless adolescents. Department of Psychiatry and Biobehavioral Sciences, 12, 80-88.

Rice, E., Kurzban, S., \& Ray, D. (2010). Homeless but connected: The role of heterogeneous social network ties and social networking technology in the mental health outcomes of street-living adolescents. Journal of Community Mental-Health, 48, 692-698.

Sakamoto I., \& Pitner, R. (2005). Use of critical consciousness in anti-oppressive social work practice: Disentangling power dynamics at personal and structural levels. Journal of British Social Work, 35, 435-452. 
Sanyal, B. (2010). From dirt road to information superhighway: Advanced information technology (AIT) and the future of the urban poor. In Wheeler, J.O., Aoyama, Y., Warf, B., (Eds.), Cities in the telecommunications age: The fracturing of geographies (143-158). New York, NY: Routledge.

Shields-Nordness, E. (2015). Social media, relationships, and young adults (Doctoral dissertation). Retrieved from Master of Social Work Clinical Research Papers. St. Catherine University. (Paper 514.)

Stergiopoulous, V., O’Campo, P., Gozdzik, A., Jeyaratnam, J., Corneau, S., Sarang, A., \& Hwang, S.W. (2012). Moving from rhetoric to reality: Adapting housing first for homeless individuals with mental illness from ethno-racial groups. BMC Health Service Research, 12, 345-359.

Subrahmanyam, K. (2010). Teens, social media, and relationships: An interview with Kaveri Subrahmanyam. The Prevention Researcher, 17. 1-1.

Subrahmanyam, K., Reich, S. M., Waechter, N., \& Espinoza, G. (2008). Online and offline social networks: Use of social networking sites by emerging adults. Journal of Applied Developmental Psychology, 29(6), 420-433.

Wheeler, J.O., Aoyama, Y., \& Warf, B., (Eds.). (2010). Cities in the telecommunications age: The fracturing of geographies. New York, NY: Routledge.

Whitbeck, L. B., \& Hoyt, D. R. (1999). Nowhere to grow: Homeless and runaway adolescents and their families. Transaction Publishers.

Williams, C. (1999). Connecting anti-racist and anti-oppressive theory and practice: Retrenchment or reappraisal? British Journal of Social Work, 29, 211-230.

Ybarra, M. L., \& Bull, S. S. (2007). Current trends in Internet-and cell phone-based HIV prevention and intervention programs. Current HIV/AIDS Reports, 4(4), 201-207.

Zide, M., \& Chery, A. (1992). A typology of runaway youths: An empirically based definition. Child and Adolescent Social Work Journal, 9, 155-168. 


\section{Appendix A.}

\section{Ryerson University}

\section{Consent Agreement}

You are being invited to participate in a research study. Please read this consent form so that you understand what your participation will involve. Before you consent to participate, please ask any questions to be sure you understand what your participation will involve.

\section{Social media among youth experiencing homelessness.}

INVESTIGATORS: This research study is being conducted by Jennifer Donath and Gordon Pon as field supervisor, from the School of Social Work at Ryerson University.

If you have any questions or concerns about the research, please feel free to contact Jennifer Donath at jdonath@ryerson.ca or Gordon Pon at the School of Social Work at 350 Victoria Street, Toronto, ON M5B 2K3. Or email g2pon@ ryerson.ca. Tel: 416-979-5000, ext. 4786. Please note that this research study is being conducted under the supervision of Gordon Pon.

PURPOSE OF THE STUDY: The purpose of this research study is to explore the impact of social media on youth experiencing homelessness. The purpose is also to explore and determine the impact of social media on the daily experiences of youth. This study will consider those who use social media such as Facebook and Instagram and who identify as homeless and currently living in a shelter. This research study is being completed by a graduate student in partial completion of the Master of Social Work (MSW) program and requirements and these results will contribute to senior projects, thesis, or dissertation.

WHAT YOU ARE EXPECTED TO DO: If you agree to be in this study, I will conduct an interview with you. The interview will be between 60-75 minutes in length and will take place in a confidential setting at an agreed upon location. The interview will be approximately 15-25 questions and will be audio recorded to ensure accurate results. All information will remain confidential and recordings will be destroyed after results have been transcribed. Questions will mainly focus on social media and the impact it has on your well-being and the reasons for using social media. An example of an interview question: describe the impact (positive or negative) social media has on your day to day? 
POTENTIAL BENEFITS: The goal of the research is to identify positive influences social media can have on individuals and help others use social media to engage in these influences, however, I cannot guarantee, that you will receive any benefits from participating in this study.

WHAT ARE THE POTENTIAL RISKS TO YOU AS A PARTICIPANT: Potential risks are low too minimal. Risks may include the recollection of past events or experiences such as loss of family, trauma, or abuse. However, the purpose of this research study is not to focus on those events, and interview questions will not touch upon these topics. At the beginning of the interview the researcher will disclose possible discomforts the participant may encounter. If this occurs, the participant has every right to decline answering a question or stop participation.

CONFIDENTIALITY: No personal information or identity will be required for the purpose of this research study. All data will be stored securely under password protection and the storage device will not be accessible to anyone except the researcher for the purpose of this study and destroyed once the study has been complete.

Due to the nature of this study and population group, the researcher will have the duty to report child abuse and neglect or suspicion of any child who is, or appears to be under the age of 16 years. This will also apply to children already under a child protection order who are 16 and 17 years old and to any reported illegal activity.

The interviews will be audio recorded for the purpose of transcribing. The participants have the right to review/edit the recordings or transcripts. The recordings will be stored in a secure office at Ryerson University in the School of Social Work. The recordings will be destroyed upon completion of research study.

By agreeing to participate in this research, you are not giving up or waiving any legal right in the event that you are harmed during the research.

Upon completion of this research study, findings will be available to participants and a copy of results will be delivered by the researcher.

Please check if you would like a copy of the research findings and results. 


\title{
VOLUNTARY PARTICIPATION AND WITHDRAWAL:
}

Participation in this study is completely voluntary. You can choose whether or not you want to be a part of this study. If any question makes you uncomfortable, you can skip that question. If you choose to stop participating, you may also choose to not have your data included in the study. Your choice of whether or not to participate will not influence your future relations with Ryerson University and the investigators involved in the research.

QUESTIONS ABOUT THE STUDY: If you have any questions about the research now, please ask. If you have questions later about the research, you may contact Jennifer Donath, Master of Social Work Student at Ryerson University at jdonath@ryerson or Gordon Pon at g2pon@ryerson.

This study has been reviewed by the Ryerson University Research Ethics Board. If you have questions regarding your rights as a participant in this study, please contact:

\author{
Research Ethics Board \\ c/o Office of the Vice President, Research and Innovation \\ Ryerson University, 350 Victoria Street \\ Toronto, ON M5B 2K3 \\ 416-979-5042 or rebchair@ryerson.ca
}

\section{CONFIRMATION OF AGREEMENT:}

Your signature below indicates that you have read the information in this agreement and have had a chance to ask any questions you have about the study. Your signature also indicates that you agree to participate in the study and have been told that you can change your mind and withdraw your consent to participate within 14 days after the interview has been conducted. You have been given a copy of this agreement. You have been told that by signing this consent agreement you are not giving up any of your legal rights.

Name of Participant (please print) 
I agree to be audio-recorded for the purposes of this study. I understand how these recordings will be stored and destroyed. 


\section{Appendix B.}

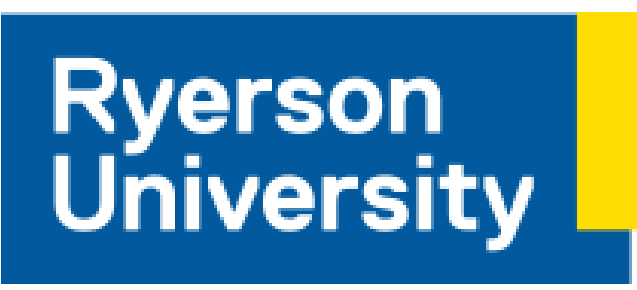

RESEARCH PARTICIPANTS NEEDED

Are you an individual that identifies as homeless or living in a shelter, with no fixed address and have access to a cell phone or computer? Do you use social media (Facebook, Instagram) to engage with others? Would you like to share your story about the impact social media has on your current well-being?

What: A one to one interview where you can share your experiences. The interview will last one hour in length.

Where: A private location at your organization. Further details will be given upon being selected. Light refreshments will be provided.

Who: To participate you must meet the following criteria: 
-No fixed address

-Living in a shelter or on the street

-Have access to social media

-Under 25 years of age

\section{You will be reimbursed for TTC costs with two tokens. \\ For more information or to participate, please email Jennifer Donath at jdonath@ryerson.ca}

This study is being conducted by a graduate student as requirement for program completion, and has been approved by the Ryerson Research Ethics Board. Research supervisor, Gordon Pon, can be reached atg2pon @ryerson.ca 


\section{Appendix C.}

\section{Interview Guide REB}

1. Do you have access to a computer? Or cell phone? How often do you use the computer/phone for social media purposes?

2. How many times a day/week do you use social media?

3. Why do you use social media?

4. What common social media sites do you most frequently use and why?

5. How has using social media connected you to friends, family, community, supports?

6. Do you find social media plays a large part in your current life? Why or why not?

7. Do you feel using social media has had an important influence on you? And how?

8. Are you part of a social network or have an online group you use? If so can you explain in more detail about that group?

9. What has been your experience with social media? Good and bad?

10. Has social media helped you become part of a certain community you otherwise would have not been connected too? Please explain.

11. Can you tell me about a positive experience using social media?

12. Can you tell me about a negative experience using social media?

13. How long have you been homeless for? If you are not currently homeless, when was the last time you did not have a permanent address?

14. Can you define what it means to be homeless in your own words?

15. Have you ever had your own place? If yes, how did that make you feel?

16. Do you have connections to family? friends?

17. Can you describe those connections?

18. Can you tell me what brought you to this shelter/streets?

19. Do you use social media as a tool to talk about your current living situation?

20. Does access to social media help you in any way? And if yes, how? If no, why not?

21. Have you met people through social media that have had the same experiences as you?

22. How has social media connected you together?

23. Are you a part of any homeless groups, advocacy groups on social media?

24. Have you had a social interaction online that you would be unable to in real life?

25. Have you ever been bullied or targeted or made to feel on comfortable while using social media?

26. Is there anything else you would like to tell me about your experiences with homelessness and social media? 